\title{
Vapor pressures and thermophysical properties of selected ethanolamines
}

\author{
Bruna P. Soares a, b, Vojtěch Štejfa ${ }^{b}$, Olga Ferreira ${ }^{a, c}$, Simão P. Pinho ${ }^{\text {a, c }}$, \\ Květoslav Rủžička ${ }^{\mathrm{b}}$, Michal Fulem ${ }^{\mathrm{b}, *}$ \\ a Associate Laboratory LSRE-LCM, Departamento de Tecnologia Química e Biológica, Instituto Politécnico de Bragança, 5300-253, Bragança, Portugal \\ ${ }^{\mathrm{b}}$ Department of Physical Chemistry, University of Chemistry and Technology, Prague, Technická 5, CZ, 16628, Prague, Czech Republic \\ c Centro de Investigação de Montanha CIMO, Instituto Politécnico de Bragança, Campus de Santa Apolónia, Bragança, Portugal
}

\section{A R T I C L E I N F O}

\section{Article history:}

Received 15 March 2018

Received in revised form 28 May 2018

Accepted 29 May 2018

Available online 2 June 2018

\section{Keywords:}

Ethanolamines

Vapor pressure

Heat capacity

Vaporization and sublimation enthalpy

Phase behavior

\begin{abstract}
A B S T R A C T
A thermodynamic study of three ethanolamines, 2-(diethylamino)ethanol, 2-(ethylamino)ethanol and 2(isopropylamino)ethanol, reporting the measurements of vapor pressure, liquid phase heat capacities, and phase behavior is presented in this work. The vapor pressures were measured using a static method in the temperature interval $238-343 \mathrm{~K}$. After a critical assessment of literature data, selected experimental data were correlated using the Cox equation. The liquid phase heat capacities were measured in the temperature range $265-355 \mathrm{~K}$ using Tian-Calvet calorimetry and the phase behavior was investigated using differential scanning calorimetry (DSC) starting from $183 \mathrm{~K}$. For 2-(ethylamino)ethanol and 2-(isopropylamino)ethanol, two monotropically related crystalline forms were identified. To our knowledge, vapor pressure and heat capacity for 2-(isopropylamino)ethanol and phase behavior data for 2-(ethylamino)ethanol and 2-(isopropylamino)ethanol are reported for the first time in this work.
\end{abstract}

(C) 2018 Elsevier B.V. All rights reserved.

\section{Introduction}

One of the most common processes applied for the capture and separation of carbon dioxide from gas streams is chemical absorption and regeneration using aqueous solutions of amines as solvent systems. In particular, 2-aminoethanol has been widely studied because of its high $\mathrm{CO}_{2}$ absorption capacity, high water solubility, and low price [1].

Meanwhile, new amines were synthetized by systematically modifying their alkyl structure and the relative position of the hydroxyl group [2], and their absorption performance was screened (e.g. absorption rate and capacity, cyclic capacity), with the aim to find alternative solvents that would enable $\mathrm{CO}_{2}$ capture with a lower energy consumption than the commercially used 2aminoethanol, as recently reviewed by Bernhardsen and Knuutila [3].

Among the most promising absorbents, the tertiary amine 2(diethylamino)ethanol [4,5], and two secondary amines, 2-(ethylamino)ethanol [6], and 2-(isopropylamino)ethanol [7,8] were

\footnotetext{
* Corresponding author.

E-mail address: fulemm@vscht.cz (M. Fulem).
}

selected for a thermodynamic characterization in this work. Structurally, they only differ in the type and number of alkyl substituents of the amine functional group.

Chowdhury et al. [4] compared the performance of 24 tertiary amine absorbents and 7 of them, including 2-(diethylamino) ethanol, were selected because of their high absorption rates and cyclic capacities. El Hadri et al. [6] also characterized 30 amines, highlighting 2-(ethylamino)ethanol as a good alternative to 2aminoethanol, presenting good carbon dioxide absorption, low heat of absorption and high kinetic reaction. Finally, Yamada et al. [8] have studied the moderately hindered amine 2-(isopropylamino)ethanol, reporting a high absorption rate and large desorption capability compared to conventional amines.

In this context, accurate vapor-liquid equilibria data are essential for the design and operation of these gas absorption processes, starting with the temperature dependence of the vapor pressure of the pure alkanolamines, which is one of the targets of this work. Environmental aspects regarding the absorbents should be also considered [9], where the knowledge of their volatility is essential to assess the potential emissions. A preliminary inspection of the available vapor pressure data showed that there were no reliable data for these compounds, except the high-accuracy ebulliometric measurements for 2-(diethylamino)ethanol [10], which are 
however restricted to elevated temperatures.

Therefore, the vapor pressures of the three ethanolamines were measured by a static method in the temperature ranges covering ambient and sub-ambient temperatures and critically compared to the available literature data. The liquid heat capacity of the solvent is also a key pure component property in the design of these absorption processes. Although the $\mathrm{CO}_{2}$ rich stream after absorption contains a solvent $-\mathrm{CO}_{2}$ reaction product, it may be assumed that a solvent with low heat capacity will enable the reduction of the sensible heat required in the desorption step [11]. Hence, the vapor pressure data were supplemented by the measurement of liquid phase heat capacities using Tian-Calvet calorimetry and phase behavior studies performed by differential scanning calorimetry (DSC). The collected information was used to derive the correspondent vaporization/sublimation enthalpies and the mutual consistency of the data was discussed.

\section{Experimental procedure}

\subsection{Materials}

The description of the samples used in this work, including their purity and purity analysis, is listed in Table 1 . The purity of samples was considered satisfactory and no further purification except drying over $4 \AA$ molecular sieves was performed. The samples were handled under dry nitrogen atmosphere in a glovebox (MBraun LabStar).

\subsection{Vapor pressure measurements}

Vapor pressures were primarily measured at ambient temperatures (below $308 \mathrm{~K}$ ) using the static apparatus STAT 6. As there were no literature data for comparison in the case of the 2-(isopropylamino)ethanol, the measurements were repeated using the STAT 8 apparatus to obtain independent results and extend the study to higher temperatures (up to $343 \mathrm{~K}$ ). The STAT6 and STAT8 apparatus were previously described in detail $[12,13]$, and thus only a concise description is provided here.

The STAT6 apparatus was built using all-metal, pneumatically operated angle valves appropriate for ultra-high vacuum (series 57, VAT Vacuumvalves AG, Switzerland) and stainless steel electrochemically polished tubing. Two absolute capacitance diaphragm gauges (CDGs) kept at $318 \mathrm{~K}$ by an internal temperature controller were used to simultaneously measure the pressure (Baratron 690A01TRA (up to $133 \mathrm{~Pa}$ ), Baratron 690A11TRA (up to $1333 \mathrm{~Pa}$ ), MKS Instruments, USA). A four-wire platinum resistance thermometer was used to measure the temperature of the sample. The platinum resistance thermometer and the CDGs were calibrated as described by Fulem et al. [12]. The standard uncertainty associated to the pressure measurements using the CDGs was $u$ $\left(p_{\mathrm{CDG}}\right)=0.0005 p_{\mathrm{CDG}}$ and the standard uncertainty of the sample temperature was $u(T)=0.02 \mathrm{~K}$. To check the performance of the STAT6 apparatus, the vapor pressure of naphthalene [14], $n$-octane and $n$-decane was measured. These data agreed with the recommended values $[14,15]$ considering the combined expanded uncertainty of the STAT6 apparatus which can be estimated, with 0.95 level of confidence $(k=2)$, as $U_{\mathrm{c}}(p / \mathrm{Pa})=0.005 p / \mathrm{Pa}+0.05$.

STAT8 was also built of stainless steel internally electrochemically polished tubing and all-metal, pneumatically operated, angle valves (VAT series 57, VAT Vacuumvalves AG, Switzerland) for ultrahigh vacuum. A CDG (Barocel 659, Edwards, UK) was used to measure the pressure with an upper limit of $1333 \mathrm{~Pa}$. An internal temperature controller kept the temperature of the pressure sensor at $T=396 \mathrm{~K}$. The temperature of the sample was measured by a secondary reference thermistor silicon-bead probe (Hart $5611 \mathrm{~A}$, Fluke, USA) in a four-wire connection. Both CDG and thermistor were calibrated as described by Štejfa et al. [13]. The standard uncertainty of the pressure measurements by the CDGs was $u$ $\left(p_{\mathrm{CDG}}\right)=0.001 p_{\mathrm{CDG}}$ and the standard uncertainty of the sample temperature was $u(T)=0.01 \mathrm{~K}$. Three reference materials (naphthalene, $n$-decane, and ferrocene) were used to calibrate the equipment over the whole working range. For the STAT8 apparatus, the combined expanded uncertainty of the vapor pressure measurements $U_{\mathrm{c}}(p)$ was estimated, with 0.95 level of confidence $(k=2)$, considering the deviations of the experimental data from the recommended values [14-16] as: $U_{\mathrm{c}}(p / \mathrm{Pa})=0.01 p / \mathrm{Pa}+0.05$.

The vapor pressure measurements were repeated several times, at given temperatures, varying them randomly so that systematic errors caused by insufficient degassing of the sample could be detected. A full automation of the apparatus allowed performing a high number of measuring cycles resulting typically in a decrease of pressure with the number of measuring cycles. The sample was considered completely degassed when the pressure decrease was negligible. Then, the final set of data was recorded, usually after performing tens to hundreds of measuring cycles at selected temperatures. For each temperature, at least three experimental points were measured.

\subsection{Calorimetric measurements}

The phase behavior was studied with the differential scanning calorimeter TA DSC Q1000 (TA Instruments, USA), starting from $T=183.15 \mathrm{~K}$. The continuous method was applied with heating rate from 0.5 to $10 \mathrm{~K} \mathrm{~min}^{-1}$. A sample load was determined using a periodically calibrated analytical balance $(0.01 \mathrm{mg}$ readability). Prior to the measurements of alkanolamines, a comprehensive temperature and enthalpy calibration of the calorimeters was carried out using five reference materials: water, gallium, naphthalene, indium, and tin.

A Tian-Calvet calorimeter Setaram $\mu$ DSC IIIa (Setaram, France) was used to measure the heat capacities of condensed phases. The continuous method was applied [17], in the temperature range from 265 to $355 \mathrm{~K}$, with a heating rate of $0.3 \mathrm{~K} \mathrm{~min}^{-1}$, and isothermal delays of $2600 \mathrm{~s}$ before and after the continuous heating. Around 10,000 experimental heat capacity data points were obtained after applying standard procedures such as slope

Table 1

Sample description.

\begin{tabular}{|c|c|c|c|c|}
\hline Chemical name & CAS RN & Source & Water content ${ }^{\mathrm{a}}$ & Mole fraction purity \\
\hline 2-(diethylamino)ethanol & $100-37-8$ & Merck & $2.6 \times 10^{-4}$ & $0.999^{b} ; 0.997^{c}$ \\
\hline 2-(ethylamino)ethanol & $110-73-6$ & Sigma Aldrich & $2.5 \times 10^{-4}$ & $0.999^{\mathrm{b}} ; 0.997^{\mathrm{c}}$ \\
\hline 2-(isopropylamino)ethanol & $109-56-8$ & TCI & $2.5 \times 10^{-4}$ & $0.992^{\mathrm{b}} ; 0.991^{\mathrm{c}}$ \\
\hline
\end{tabular}

a Mass fraction of water determined by Karl-Fischer analysis by Metrohm 831 .

b Purity provided by the manufacturer in the certificate of analysis. Purity was determined by gas-liquid chromatography (GLC) in all cases.

c Purity determined by GLC using the Hewlett-Packard 6890 chromatograph equipped with a column HP-1, length $25 \mathrm{~m}$, film thickness $0.52 \mathrm{~mm}$, diameter 0.30 mm, and FID detector. The average was of at least two determinations. 
Table 2

Experimental vapor pressures $p$ measured in this work.

\begin{tabular}{|c|c|c|c|c|c|c|c|c|}
\hline$T / \mathrm{K}$ & $p / \mathrm{Pa}^{\mathrm{a}}$ & $\Delta p / \mathrm{Pa}^{\mathrm{b}}$ & $T / \mathrm{K}$ & $p / \mathrm{Pa}^{\mathrm{a}}$ & $\Delta p / \mathrm{Pa}^{\mathrm{b}}$ & $T / \mathrm{K}$ & $p / \mathrm{Pa}^{\mathrm{a}}$ & $\Delta p / \mathrm{Pa}^{\mathrm{b}}$ \\
\hline \multicolumn{3}{|c|}{ 2-(diethylamino)ethanol } & \multicolumn{3}{|c|}{ 2-(ethylamino)ethanol } & \multicolumn{3}{|c|}{ 2-(ethylamino)ethanol } \\
\hline \multicolumn{3}{|c|}{ liquid phase (STAT6) ${ }^{c}$} & \multicolumn{3}{|c|}{ liquid phase $\left(\right.$ STAT6) ${ }^{c}$} & \multicolumn{3}{|c|}{ crystalline $\alpha$-form (STAT6) ${ }^{c}$} \\
\hline 273.64 & 34.88 & 0.11 & 243.07 & $0.222^{\mathrm{d}}$ & 0.001 & 238.05 & 0.050 & 0.002 \\
\hline 273.64 & 34.90 & 0.13 & 243.07 & $0.223^{\mathrm{d}}$ & 0.002 & 238.05 & 0.049 & 0.000 \\
\hline 273.64 & 34.89 & 0.12 & 243.07 & $0.221^{\mathrm{d}}$ & 0.000 & 238.05 & 0.048 & -0.001 \\
\hline 278.14 & 51.31 & 0.13 & 248.11 & $0.424^{\mathrm{d}}$ & 0.003 & 243.07 & 0.113 & 0.001 \\
\hline 278.15 & 51.34 & 0.15 & 248.11 & $0.423^{\mathrm{d}}$ & 0.002 & 243.07 & 0.112 & 0.000 \\
\hline 278.14 & 51.33 & 0.12 & 248.11 & $0.423^{\mathrm{d}}$ & 0.002 & 243.07 & 0.113 & 0.000 \\
\hline 283.15 & 77.37 & 0.08 & 253.13 & $0.783^{\mathrm{d}}$ & 0.004 & 248.13 & 0.251 & -0.001 \\
\hline 283.14 & 77.33 & 0.09 & 253.13 & $0.784^{\mathrm{d}}$ & 0.005 & 248.13 & 0.252 & 0.000 \\
\hline 283.14 & 77.33 & 0.06 & 253.13 & $0.781^{\mathrm{d}}$ & 0.002 & 248.14 & 0.253 & 0.000 \\
\hline 288.15 & 114.58 & -0.06 & 258.13 & $1.401^{\mathrm{d}}$ & 0.002 & 253.13 & 0.546 & 0.001 \\
\hline 288.15 & 114.56 & -0.08 & 258.13 & $1.403^{\mathrm{d}}$ & 0.003 & 253.13 & 0.545 & 0.000 \\
\hline 288.15 & 114.59 & -0.05 & 258.14 & $1.403^{\mathrm{d}}$ & 0.002 & 253.13 & 0.544 & -0.001 \\
\hline 293.14 & 167.01 & -0.04 & 263.13 & $2.453^{\mathrm{d}}$ & -0.001 & 258.13 & 1.146 & 0.005 \\
\hline 293.14 & 166.92 & -0.13 & 263.14 & $2.454^{\mathrm{d}}$ & -0.003 & 258.14 & 1.142 & -0.001 \\
\hline 293.14 & 166.86 & -0.19 & 263.14 & $2.454^{\mathrm{d}}$ & -0.003 & 258.14 & 1.139 & -0.004 \\
\hline 298.15 & 239.33 & -0.63 & 268.14 & 4.201 & -0.008 & 263.14 & 2.334 & 0.007 \\
\hline 298.15 & 239.32 & -0.64 & 268.14 & 4.205 & -0.004 & 263.14 & 2.326 & -0.001 \\
\hline 298.15 & 239.32 & -0.64 & 268.14 & 4.206 & -0.003 & 263.14 & 2.320 & -0.006 \\
\hline 303.15 & 338.03 & -1.28 & 273.14 & 7.045 & -0.009 & & & \\
\hline 303.14 & 337.82 & -1.21 & 273.14 & 7.039 & -0.015 & & & \\
\hline 303.14 & 337.89 & -1.30 & 273.14 & 7.052 & -0.002 & & & \\
\hline 308.15 & 470.78 & -2.34 & 278.14 & 11.58 & 0.01 & & & \\
\hline 308.15 & 470.78 & -2.34 & 278.14 & 11.58 & 0.01 & & & \\
\hline \multirow[t]{19}{*}{308.15} & 470.89 & -2.23 & 278.14 & 11.58 & 0.01 & & & \\
\hline & & & 283.14 & 18.63 & 0.02 & & & \\
\hline & & & 283.14 & 18.62 & 0.01 & & & \\
\hline & & & 283.14 & 18.62 & 0.01 & & & \\
\hline & & & 288.14 & 29.35 & -0.01 & & & \\
\hline & & & 288.14 & 29.36 & 0.01 & & & \\
\hline & & & 288.14 & 29.34 & -0.02 & & & \\
\hline & & & 293.13 & 45.45 & 0.03 & & & \\
\hline & & & 293.13 & 45.45 & 0.02 & & & \\
\hline & & & 293.13 & 45.43 & 0.01 & & & \\
\hline & & & 298.14 & 69.13 & -0.05 & & & \\
\hline & & & 298.14 & 69.15 & -0.03 & & & \\
\hline & & & 298.14 & 69.15 & -0.03 & & & \\
\hline & & & 303.13 & 103.41 & -0.03 & & & \\
\hline & & & 303.13 & 103.41 & -0.03 & & & \\
\hline & & & 303.14 & 103.48 & -0.04 & & & \\
\hline & & & 308.14 & 152.46 & 0.04 & & & \\
\hline & & & 308.14 & 152.47 & 0.05 & & & \\
\hline & & & 308.14 & 152.48 & 0.06 & & & \\
\hline \multicolumn{3}{|c|}{ 2-(isopropylamino)ethanol } & \multicolumn{3}{|c|}{ 2-(isopropylamino)ethanol } & \multicolumn{3}{|c|}{ 2-(isopropylamino)ethanol } \\
\hline liquid pha & & & liquid $\mathrm{p}$ & AT8 $)^{e}$ & & crystallin & $(\text { STAT6) })^{c}$ & \\
\hline 248.13 & $0.252^{\mathrm{d}}$ & 0.001 & 298.11 & 48.99 & -0.03 & 253.15 & 0.258 & 0.051 \\
\hline 248.13 & $0.252^{\mathrm{d}}$ & 0.001 & 298.12 & 49.20 & 0.11 & 253.15 & 0.257 & 0.050 \\
\hline 248.13 & $0.251^{\mathrm{d}}$ & 0.000 & 298.17 & 49.28 & -0.02 & 253.15 & 0.254 & 0.047 \\
\hline 253.14 & $0.472^{\mathrm{d}}$ & 0.000 & 303.04 & 74.39 & 0.15 & 258.14 & 0.482 & 0.057 \\
\hline 253.15 & $0.471^{\mathrm{d}}$ & -0.002 & 303.04 & 74.40 & 0.15 & 258.14 & 0.480 & 0.055 \\
\hline 253.15 & $0.472^{\mathrm{d}}$ & -0.001 & 303.04 & 74.35 & 0.10 & 258.14 & 0.479 & 0.054 \\
\hline 258.15 & $0.864^{\mathrm{d}}$ & -0.002 & 308.01 & 111.1 & 0.1 & 263.15 & 0.926 & 0.074 \\
\hline 258.15 & $0.864^{\mathrm{d}}$ & -0.002 & 308.03 & 111.2 & 0.0 & 263.15 & 0.923 & 0.071 \\
\hline 258.15 & $0.864^{\mathrm{d}}$ & -0.002 & 308.04 & 111.2 & 0.0 & 263.15 & 0.921 & 0.069 \\
\hline 263.15 & $1.544^{\mathrm{d}}$ & -0.002 & 313.00 & 164.0 & 0.4 & 268.14 & 1.710 & 0.050 \\
\hline 263.15 & $1.546^{\mathrm{d}}$ & -0.001 & 313.01 & 164.2 & 0.5 & 268.14 & 1.710 & 0.050 \\
\hline 263.15 & $1.544^{\mathrm{d}}$ & -0.002 & 313.01 & 164.2 & 0.4 & 268.14 & 1.709 & 0.049 \\
\hline 268.14 & $2.688^{\mathrm{d}}$ & -0.006 & 317.90 & 237.2 & 1.1 & 273.14 & 3.180 & 0.020 \\
\hline 268.14 & $2.688^{\mathrm{d}}$ & -0.006 & 317.90 & 237.2 & 1.1 & 273.14 & 3.182 & 0.022 \\
\hline 268.14 & $2.688^{\mathrm{d}}$ & -0.006 & 317.90 & 237.3 & 1.2 & 273.14 & 3.174 & 0.014 \\
\hline 273.14 & $4.591^{\mathrm{d}}$ & -0.004 & 322.97 & 340.5 & 0.2 & 278.14 & 5.875 & -0.003 \\
\hline 273.15 & $4.589^{\mathrm{d}}$ & -0.011 & 322.97 & 340.5 & 0.2 & 278.14 & 5.872 & -0.006 \\
\hline 273.15 & $4.590^{\mathrm{d}}$ & -0.010 & 322.98 & 340.7 & 0.2 & 278.14 & 5.870 & -0.008 \\
\hline 278.14 & $7.669^{d}$ & -0.004 & 327.95 & 481.4 & 0.8 & 283.14 & 10.65 & -0.04 \\
\hline 278.14 & $7.676^{\mathrm{d}}$ & 0.003 & 327.95 & 481.4 & 0.8 & 283.14 & 10.66 & -0.04 \\
\hline 278.14 & $7.665^{d}$ & -0.008 & 327.95 & 481.5 & 0.8 & 283.14 & 10.68 & -0.02 \\
\hline 283.14 & $12.57^{\mathrm{d}}$ & 0.02 & 332.99 & 673.1 & 0.6 & 288.14 & 19.09 & 0.02 \\
\hline 283.14 & $12.57^{\mathrm{d}}$ & 0.01 & 332.99 & 673.1 & 0.5 & 288.14 & 19.11 & 0.05 \\
\hline
\end{tabular}




\begin{tabular}{|c|c|c|c|c|c|c|c|c|}
\hline 283.14 & $12.57^{\mathrm{d}}$ & 0.01 & 332.99 & 672.8 & 0.3 & 288.15 & 19.10 & 0.01 \\
\hline 288.15 & $20.20^{\mathrm{d}}$ & 0.03 & 337.93 & 922.1 & -1.0 & & & \\
\hline 288.15 & $20.20^{\mathrm{d}}$ & 0.03 & 337.93 & 922.1 & -1.0 & & & \\
\hline 288.15 & $20.20^{\mathrm{d}}$ & 0.03 & 337.93 & 922.3 & -0.9 & & & \\
\hline 293.14 & 31.79 & 0.04 & 342.94 & 1256.6 & -1.2 & & & \\
\hline 293.14 & 31.79 & 0.04 & 342.94 & 1256.6 & -1.2 & & & \\
\hline 293.14 & 31.79 & 0.04 & 342.94 & 1256.8 & -1.3 & & & \\
\hline 298.14 & 49.14 & -0.02 & & & & & & \\
\hline 298.14 & 49.15 & -0.01 & & & & & & \\
\hline 298.14 & 49.15 & -0.01 & & & & & & \\
\hline 303.14 & 74.70 & -0.14 & & & & & & \\
\hline 303.14 & 74.69 & -0.15 & & & & & & \\
\hline 303.14 & 74.73 & -0.11 & & & & & & \\
\hline 308.14 & 111.86 & -0.25 & & & & & & \\
\hline 308.15 & 111.89 & -0.31 & & & & & & \\
\hline 308.15 & 111.84 & -0.36 & & & & & & \\
\hline
\end{tabular}

${ }^{\text {a }}$ Values are reported with one digit more than is justified by the experimental uncertainty to avoid round-off errors in calculations based on these results. Vapor pressure data excluded from the correlation (Eq. (1)) are in written in italics.

b $\Delta p / \mathrm{Pa}=\left(p-p_{\text {calc }}\right) / \mathrm{Pa}$, where $p_{\text {calc }}$ is calculated from the Cox equation, Eq. (1), with parameters given in Table 4.

c The standard uncertainty in the sample temperature measurements is $u(T)=0.02 \mathrm{~K}$ and combined expanded uncertainty ( 0.95 level of confidence, $k=2$ ) in the vapor pressure measurements is $U_{\mathrm{c}}(p)=0.005 p+0.05 \mathrm{~Pa}$.

d Supercooled liquid.

e The standard uncertainty in the sample temperature measurements is $u(T)=0.01 \mathrm{~K}$ and combined expanded uncertainty (0.95 level of confidence, $k=2$ ) in the vapor pressure measurements is $U_{\mathrm{c}}(p)=0.01 p+0.05 \mathrm{~Pa}$.

Table 3

Overview of the literature vapor pressure data for the studied ethanolamines. ${ }^{\text {a }}$

\begin{tabular}{|c|c|c|c|c|c|c|}
\hline Ref. & $N^{\mathrm{b}}$ & $\left(T_{\min }-T_{\max }\right) / \mathrm{K}$ & $\left(p_{\min }-p_{\max }\right) / \mathrm{kPa}$ & $u(T)^{\mathrm{c}} / \mathrm{K}$ & $u(p)^{\mathrm{d}} / \mathrm{Pa}$ & Method \\
\hline \multicolumn{7}{|c|}{ 2-(diethylamino)ethanol } \\
\hline Steele et al. [10] & 23 & $332.5-475.6$ & $2.002-269.96$ & & $0.3-20^{\mathrm{e}}$ & Ebulliometric \\
\hline Lebedeva et al. [20] & 18 & $283-318$ & $(2.95-45) \cdot 10^{-3}$ & & & Effusion \\
\hline \multirow[t]{2}{*}{ Yang et al. [21,22] } & 5 & $406.0-435.9$ & $40.00-101.30$ & $0.05[21]$ & 300 & Ebulliometric \\
\hline & & & & $0.1[22]$ & & \\
\hline Kapteina et al. [23] & 31 & $278.2-318.3$ & $(51.5-876.6) \cdot 10^{-3}$ & 0.1 & & Transpiration \\
\hline \multirow[t]{2}{*}{ Klepáčová et al. [24] } & 13 & $333.2-449.5$ & $1.94-150.0$ & 0.1 & $0.5 \%(p<50 \mathrm{kPa})$ & Ebulliometric \\
\hline & & & & & $0.2 \%(50 \mathrm{kPa}<p)$ & \\
\hline This work $\left(\right.$ STAT6) $^{\mathrm{f}}$ & 24 & $273.6-308.2$ & $(34.9-470.9) \cdot 10^{-3}$ & 0.02 & $0.005 p+0.05^{f}$ & Static \\
\hline \multicolumn{7}{|l|}{ 2-(ethylamino)ethanol } \\
\hline Kapteina et al. [23] & 17 & $282.5-321.3$ & $(16.3-374.0) \cdot 10^{-3}$ & 0.1 & & Transpiration \\
\hline This work (STAT6) & 60 & 238.1-308.1 & $(0.050-152.5) \cdot 10^{-3}$ & 0.02 & $0.005 p+0.05^{\mathrm{f}}$ & Static \\
\hline \multicolumn{7}{|c|}{ 2-(isopropylamino)ethanol } \\
\hline This work (STAT6) & 54 & 248.1-308.2 & $(0.252-111.8) \cdot 10^{-3}$ & 0.02 & $0.005 p+0.05^{\mathrm{f}}$ & Static \\
\hline This work (STAT8) & 39 & 298.1-342.9 & $(49.0-1257) \cdot 10^{-3}$ & 0.01 & $0.01 p+0.05^{\mathrm{f}}$ & Static \\
\hline
\end{tabular}

a The vapor pressure data sets written in bold were correlated by Cox equation, Eq. (1). The parameters of this equation are listed in Table 4.

b $N$ stands for the number of experimental points.

c $u(T)=$ uncertainty in temperature when reported by the authors.

d $u(p)=$ uncertainty in pressure when reported by the authors.

e The uncertainty in vapor pressure was reported for each individual experimental point. The uncertainty at $T_{\min }$ and $T_{\max }$ is given in the table.

$\mathrm{f}$ The uncertainties reported for the measurements performed in this work are the standard uncertainty $(k=1)$ for temperature and combined expanded uncertainty $(0.95$ level of confidence, $k=2$ ) for vapor pressure.

Table 4

Parameters of the Cox equation, Eq. (1).

\begin{tabular}{|c|c|c|c|c|c|c|c|c|c|}
\hline Compound & Phase & $T_{0} / \mathrm{K}$ & $p_{0} / \mathrm{Pa}$ & $A_{0}$ & $A_{1} \cdot 10^{3}$ & $A_{2} \cdot 10^{6}$ & $T_{\min }-T_{\max }(\mathrm{K})$ & $\sigma^{\mathrm{a}} / \mathrm{Pa}$ & $\sigma_{\mathrm{r}}{ }^{\mathrm{a}} / \%$ \\
\hline 2-(diethylamino)ethanol & Liquid & 298.15 & 239.946 & 3.41779 & -1.60983 & 1.25256 & $273.6-475.6$ & 14 & 0.22 \\
\hline 2-(ethylamino)ethanol & Liquid & 264.99 & 3.0071 & 3.34088 & 0.56944 & -1.92614 & $243.1-308.1$ & 0.02 & 0.28 \\
\hline 2-(ethylamino)ethanol & Crystalline $\alpha$-form ${ }^{\mathrm{b}}$ & 264.99 & 3.0071 & 3.59607 & 0 & 0 & $238.1-263.1$ & 0.003 & 1.0 \\
\hline 2-(isopropylamino)ethanol & Liquid & 290.81 & 25.7481 & 3.28494 & 0.44491 & -1.66274 & $248.1-342.9$ & 0.5 & 0.21 \\
\hline 2-(isopropylamino)ethanol & Crystalline $\alpha$-form ${ }^{\mathrm{b}}$ & 290.81 & 25.7482 & 3.47900 & 0 & 0 & $273.1-288.1$ & 0.03 & 0.39 \\
\hline
\end{tabular}

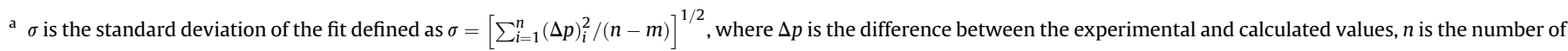

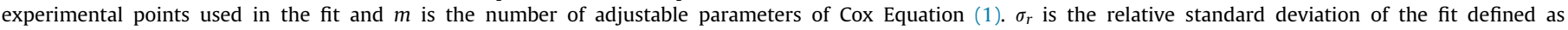
$\sigma_{r}=\left[\sum_{i=1}^{n}(\Delta \ln p)_{i}^{2} /(n-m)\right]^{1 / 2}$.

b Thermodynamically stable crystalline form. For details on the polymorphic behavior, see section 3.3. 

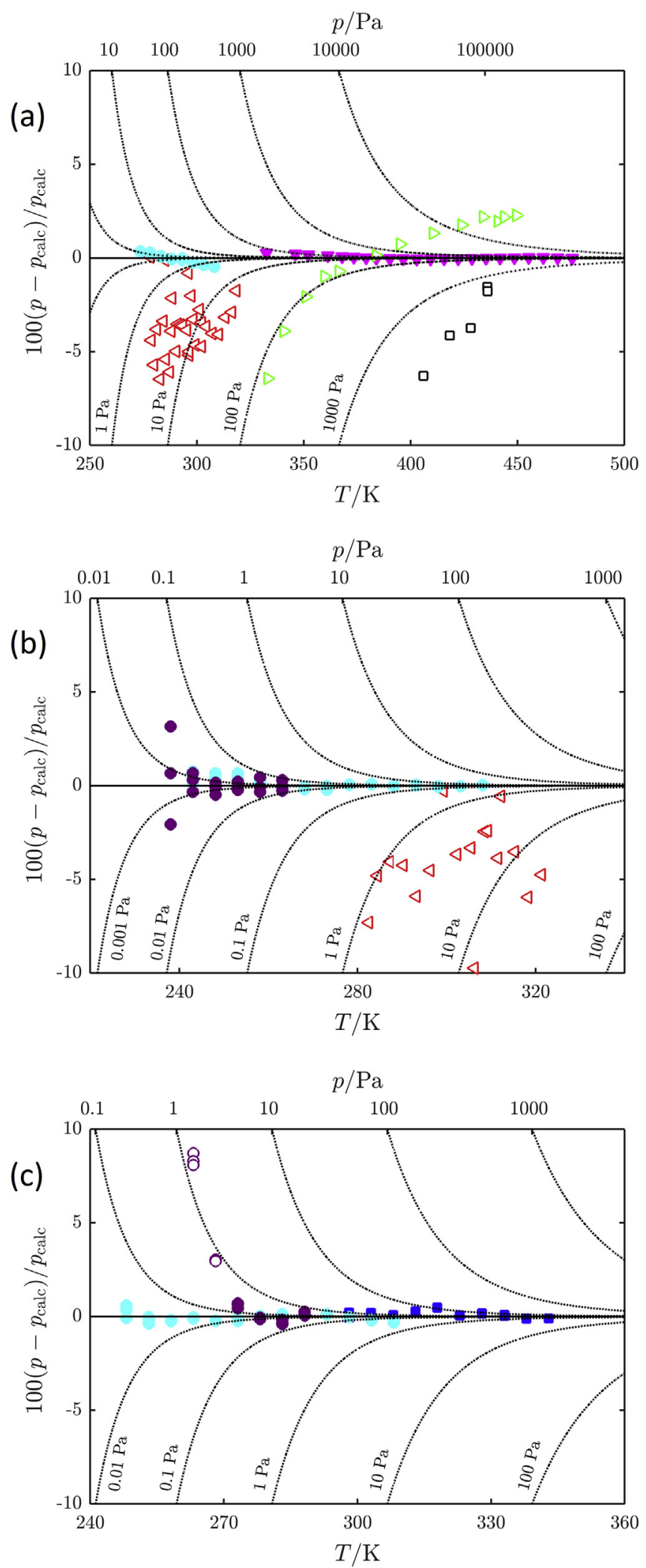

Fig. 1. Deviations of experimental vapor pressures $p$ from values calculated using the Cox equation, Eq. (1), $p_{\text {calc }}$ a) 2-(diethylamino)ethanol, b) 2-(ethylamino)ethanol, c) 2(isopropylamino)ethanol., this work (liquid phase, STAT6); $\bigcirc$, this work (crystalline phase, STAT6); $\mathbf{\square}$, this work (liquid phase, STAT8); $\triangleright$, Klepáčová et al. [24]; $\nabla$, Steele et al. [10]; $\triangleleft$, Kapteina et al. [23]; $\square$, Yang et al. [21,22]. Deviations of the data reported by Lebedeva et al. [20] are out of the scale. Filled symbols represent data included in the correlation using the Cox equation, Eq. (1).

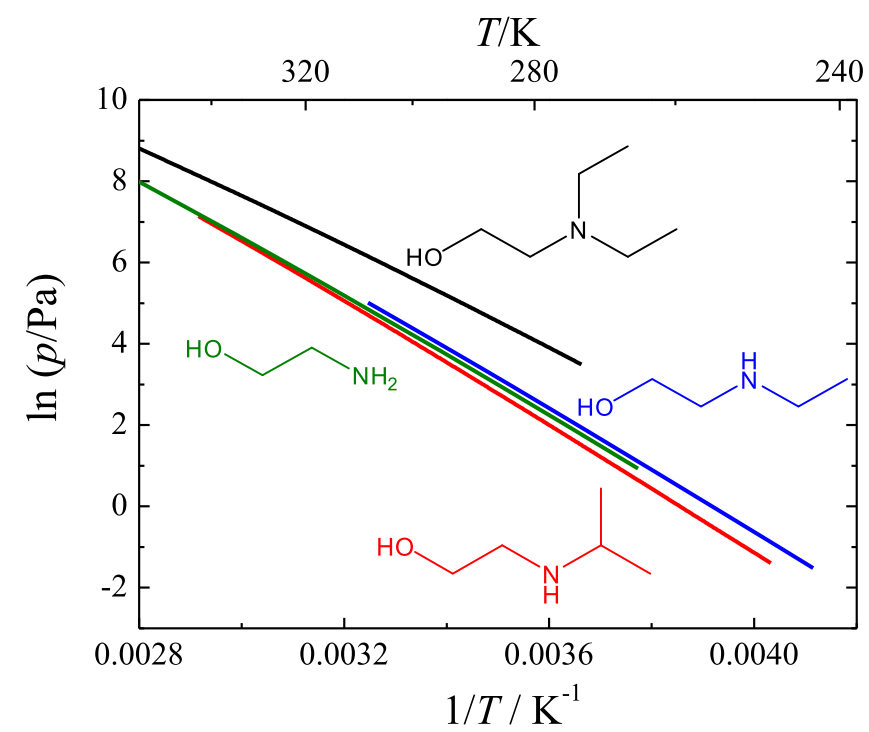

Fig. 2. Comparison of vapor pressure of the studied ethanolamines and 2aminoethanol in the liquid phase (smoothed data obtained from the Cox equation, Eq. (1) are presented). —, 2-(diethylamino)ethanol $\left(M=117.19 \mathrm{~g} \mathrm{~mol}^{-1}\right) ;-, 2$-(ethylamino)ethanol $\quad\left(M=89.14 \mathrm{~g} \mathrm{~mol}^{-1}\right), \quad$ - $\quad$ 2-(isopropylamino)ethanol $\left(M=103.16 \mathrm{~g} \mathrm{~mol}^{-1}\right),-, 2$-aminoethanol $\left(M=61.08 \mathrm{~g} \mathrm{~mol}^{-1}\right.$, recommended data [26]).

correction, signal smoothing, and heat capacity calculation from the heat flow record of the empty sample cell, the sample cell filled with the reference compound and, finally, with the sample. The heat capacities presented here result from averaging the raw heat capacity data measured by the continuous method, over $5 \mathrm{~K}$ intervals, being reported at the mean temperature of the corresponding $5 \mathrm{~K}$ interval. The heat capacity measurements have an estimated combined expanded uncertainty $U_{\mathrm{c}}\left(C_{p, \mathrm{~m}}\right)=0.01 C_{p, \mathrm{~m}}$. The calorimeter and its calibration are described in detail in the work of Straka et al. [18].

\section{Results and discussion}

\subsection{Vapor pressures}

The experimental vapor pressures obtained in this work using the STAT6 and STAT8 apparatus are given in Table 2. The vapor pressures of 2-(diethylamino)ethanol were measured in a shorter temperature interval due to a continuous decay of the sample purity, which was manifested by divergence of the time dependence of the observed pressure at a single temperature instead of convergence to a stable final value (degassed state). Similar behavior was observed e.g. during measurements of limonene [19]. The presented values were obtained in the time interval of the lowest decreases of the observed pressure between two measurement cycles at the same temperature. At this stage of the experiment, the volatile impurities were already eliminated by the degassing process, but the less volatile impurities did not significantly affect the vapor pressure readings yet. The purity of 2(diethylamino)ethanol after vapor pressure measurements was approximately equal to the initial one, however the distribution of impurities changed towards a higher concentration of less volatile impurities.

For 2-(ethylamino)ethanol and 2-(isopropylamino)ethanol, the vapor pressure data for the crystalline $\alpha$-form were also determined (see section 3.3. for details on polymorphic behavior of the studied compounds). The vapor pressure measurements in the crystalline phase were performed only after completing of 
Table 5

Experimental liquid heat capacities $C_{p, \mathrm{~m}}^{\mathrm{l}}$ for the alkanolamines studied in this work.

\begin{tabular}{llll}
\hline$T / \mathrm{K}$ & $C_{p, \mathrm{~m} / \mathrm{J} \cdot \mathrm{mol}^{-1} \cdot \mathrm{K}^{-1}}$ & & \\
\cline { 2 - 4 } & 2 -(diethylamino)ethanol & 2 -(ethylamino)ethanol & $240.4^{\mathrm{a}}$ \\
\hline 265.0 & 260.6 & 215.4 & $243.1^{\mathrm{a}}$ \\
270.0 & 263.9 & 217.1 & $245.8^{\mathrm{a}}$ \\
275.0 & 267.1 & 218.8 & $248.5^{\mathrm{a}}$ \\
280.0 & 270.0 & 220.3 & $251.0^{\mathrm{a}}$ \\
285.0 & 272.8 & 222.0 & 253.8 \\
290.0 & 275.6 & 223.6 & 256.9 \\
295.0 & 278.7 & 225.5 & 260.1 \\
300.0 & 281.8 & 227.7 & 263.3 \\
305.0 & 284.7 & 229.9 & 266.6 \\
310.0 & 287.6 & 232.1 & 270.1 \\
315.0 & 290.5 & 234.6 & 273.5 \\
320.0 & 293.2 & 237.0 & 277.2 \\
325.0 & 295.8 & 239.5 & 280.7 \\
330.0 & 298.2 & 242.0 & 284.3 \\
335.0 & 300.4 & 244.4 & 287.7 \\
340.0 & 302.7 & 247.0 & 291.1 \\
345.0 & 305.1 & 249.9 & 294.9 \\
350.0 & 307.7 & 252.9 & 298.5 \\
355.0 & 309.9 & 255.9 & \\
\hline
\end{tabular}

a Supercooled liquid.

Table 6

Overview of the literature liquid phase heat capacity data for the studied ethanolamines. ${ }^{\mathrm{a}}$

\begin{tabular}{|c|c|c|c|c|}
\hline Reference & $N^{\mathrm{b}}$ & $\left(T_{\min }\right.$ to $\left.T_{\max }\right) / \mathrm{K}$ & $u_{\mathrm{r}}\left(C_{p, \mathrm{~m}}\right)^{\mathrm{c}} / \%$ & Method \\
\hline \multicolumn{5}{|c|}{ 2-(diethylamino)ethanol } \\
\hline Steele et al. [10] & $S^{\mathrm{d}}$ & $293-458$ & 1 & PC-DSC ${ }^{\mathrm{e}}$ \\
\hline Maham et al. [27] & 5 & $299-398$ & 0.9 & Tian-Calvet \\
\hline This work & 19 & $265-355$ & 1 & Tian-Calvet \\
\hline \multicolumn{5}{|c|}{ 2-(ethylamino)ethanol } \\
\hline Maham et al. [27] & 5 & $299-398$ & 0.9 & Tian-Calvet \\
\hline This work & 19 & $265-355$ & 1 & Tian-Calvet \\
\hline \multicolumn{5}{|c|}{ 2-(isopropylamino)ethanol } \\
\hline This work & 19 & $265-355$ & 1 & Tian-Calvet \\
\hline
\end{tabular}

${ }^{\text {a }}$ Only heat capacity data determined in this work were used in the correlation using Eq. (2) and developing the parameters listed in

Table 7.

b Number of experimental points.

c $u_{r}\left(C_{p, \mathrm{~m}}\right)$ stands for relative uncertainty as stated by the authors.

d Only smoothed data represented by a linear equation were reported.

e Power-compensation DSC.

degassing of the sample in the liquid phase. For 2-(isopropylamino) ethanol, the data in the temperature range (253-268) $\mathrm{K}$ were excluded from the correlation for the crystalline phase due to higher uncertainties of these experimental points.

A summary of the vapor pressure data from this work and literature is presented in Table 3. To our knowledge no vapor pressure data for 2-(isopropylamino)ethanol were reported in the literature. The data selected for the correlation are given in bold in Table 3. The ebulliometric measurements by Steele et al. [10] are the most reliable among the vapor pressure data reported for 2(diethylamino)ethanol. Other literature sources, i.e. Lebedeva et al. [20], Yang et al. [21,22], Kapteina et al. [23], and Klepáčová et al. [24] were not used in the correlation due to their higher uncertainty, large scatter and the vapor pressure temperature dependence differing from that obtained in this work and by Steele et al. [10]. The selected vapor pressure data sets were correlated using the Cox equation [25]:

$\ln \frac{p}{p_{0}}=\left(1-\frac{T_{0} / K}{T / K}\right) \exp \left(\sum_{i=0}^{n} A_{i}(T / K)^{i}\right)$

where $T_{0}$ and $p_{0}$ are the temperature and pressure of an arbitrarily chosen reference point and the $A_{i}$ are the correlation parameters. $n=2$ is usually adequate but fewer parameters can be used for a narrow temperature range, as in the case of crystalline phases in

Table 7

Parameters of the polynomial Eq. (2) for the liquid heat capacities and standard deviation of the fit $\sigma$.

\begin{tabular}{|c|c|c|c|c|c|c|}
\hline Compound & $A_{1}$ & $A_{2}$ & $A_{3}$ & $T_{\min } / K$ & $T_{\max } / K$ & $\sigma^{\mathrm{a}}$ \\
\hline 2-(diethylamino)ethanol & 1.14899 & 14.9673 & -1.34970 & 265.0 & 355.0 & 0.029 \\
\hline 2-(ethylamino)ethanol & 31.4201 & -7.65954 & 2.10650 & 265.0 & 355.0 & 0.020 \\
\hline 2-(isopropylamino)ethanol & 24.1550 & -2.73036 & 1.70497 & 265.0 & 355.0 & 0.035 \\
\hline
\end{tabular}

${ }^{\mathrm{a}} \sigma=\left[\sum_{i=1}^{n}\left(C_{p, \mathrm{~m}}^{\mathrm{l}} / R-C_{p, \mathrm{~m}}^{\mathrm{l}, \mathrm{malc}} / R\right)_{i}^{2} /(n-m)\right]^{1 / 2}$, where $n$ is the number of fitted data points and $m$ is the number of adjustable parameters. 

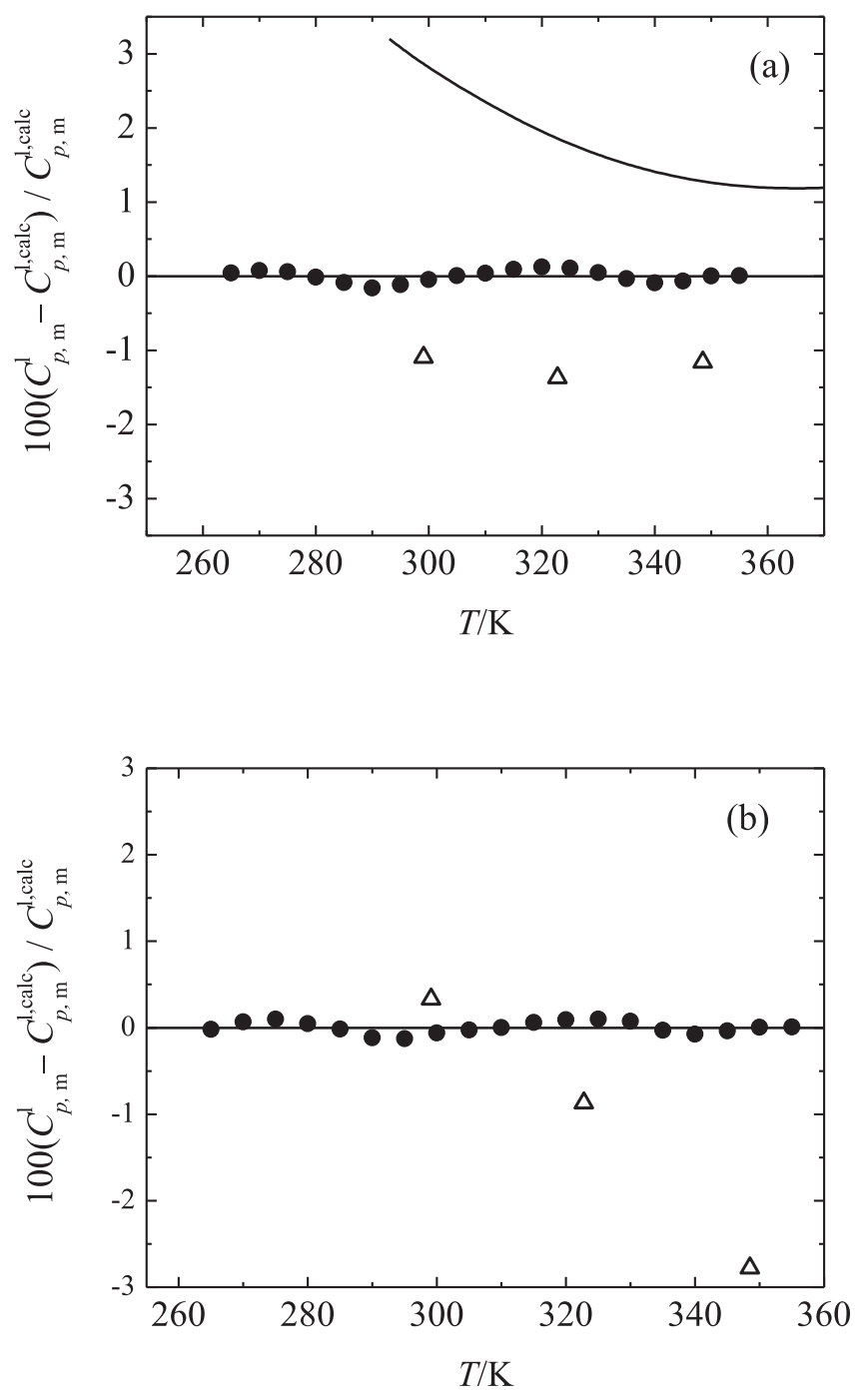

Fig. 3. Deviation of experimental liquid phase heat capacities $C_{p, \mathrm{~m}}^{\mathrm{l}}$ from the values $C_{p, \mathrm{~m}}^{\mathrm{l}, \text { calc }}$ calculated using Eq. (2) and parameters listed in Table 7 a) 2-(diethylamino) ethanol, b) 2-(ethylamino)ethanol. @, this work; -, Steele et al. [10] (smoothed data); $\triangle$, Maham et al. [27]. Filled symbols represent data included in the correlation using Eq. (2)

this work. The parameters of the Cox equation, Eq. (1), are presented in Table 4. Fig. 1 shows the deviations of the literature values from the Cox equation, Eq. (1), for the entire temperature range studied, stressing the high relevance of the new vapor pressure measurements as large scatter can be observed for certain published data.

Fig. 2 compares the vapor pressure data in the liquid phase for the three studied ethanolamines. The recommended vapor pressure data for 2-aminoethanol [26] are also included for comparison. The tertiary amine, 2-(diethylamino)ethanol, has the highest vapor pressure and, the secondary amine, 2-(isopropylamino) ethanol, the lowest. Structurally, all the studied ethanolamines have in common a hydroxyl group that can self-associate and cross-associate with the amine group. On the other hand, the amine group cannot self-associate in the case of tertiary amines. In fact, tertiary amines have typically higher vapor pressures than secondary or primary amines with the same molecular weight, due to the absence of hydrogen bonding in the disubstituted amine group and, hence, weaker intermolecular interactions. This effect prevails with the ethanolamines studied in this work as the
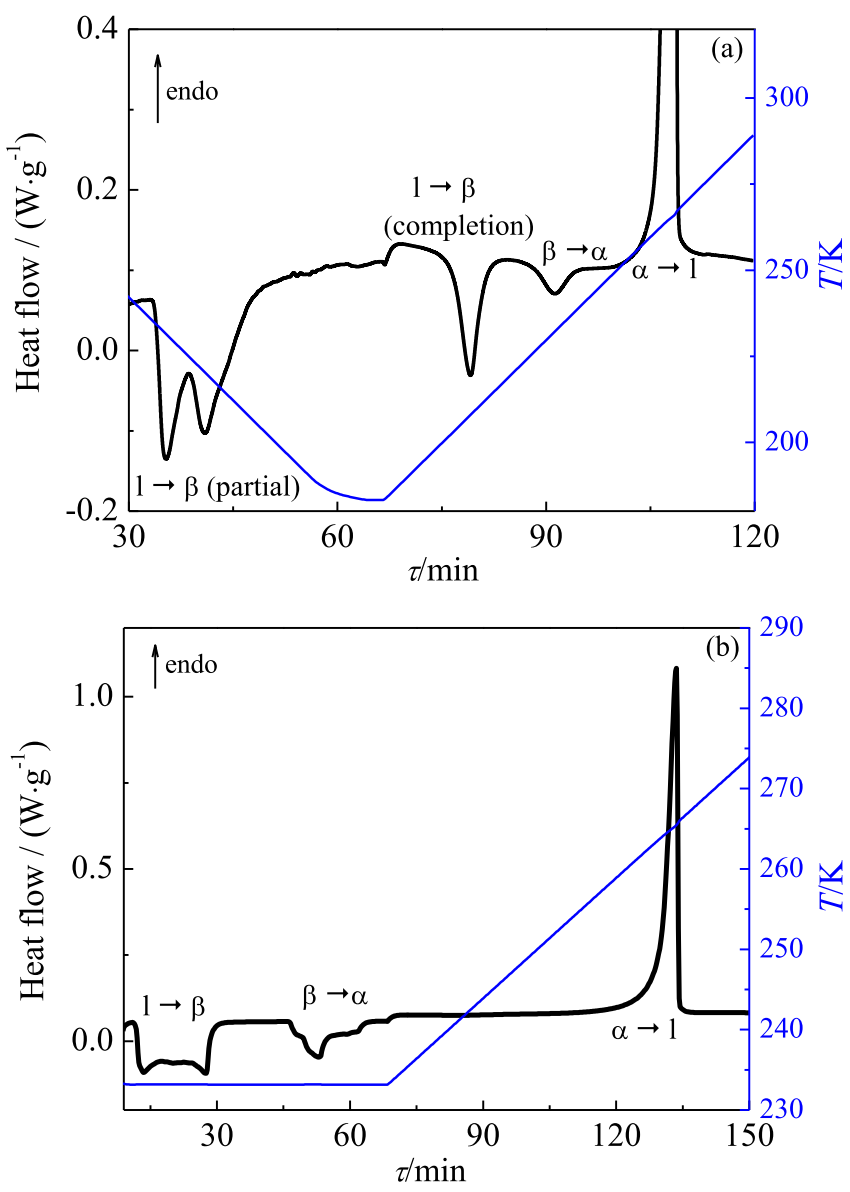

Fig. 4. DSC thermograms 2-(ethylamino)ethanol. - temperature program, - , heat flow. (a) The sample was cooled down to $183 \mathrm{~K}$ at a cooling rate of $2 \mathrm{~K} \cdot \mathrm{min}^{-1}$ (it partially crystallized to the metastable $\beta$-form) and subsequently heated at a heating rate $2 \mathrm{~K} \cdot \mathrm{min}^{-1}$. (b) After cooling by $10 \mathrm{~K} \cdot \mathrm{min}^{-1}$ to $233 \mathrm{~K}$ (no crystallization was observed) the sample was kept at $233 \mathrm{~K}$ for $60 \mathrm{~min}$ and subsequently heated at a rate of $0.5 \mathrm{~K} \cdot \mathrm{min}^{-1}$ (repeating this temperature program resulted in identical thermograms).

tertiary amine, with the highest molecular weight, has a higher vapor pressure than both secondary amines between which, as expected, 2-(ethylamino)ethanol has a higher vapor pressure than the heavier 2-(isopropylamino)ethanol.

\subsection{Liquid phase heat capacity}

The experimental heat capacities for the studied ethanolamines obtained in this work in the temperature range from $265 \mathrm{~K}$ to $355 \mathrm{~K}$ using a Tian-Calvet calorimeter are listed in Table 5. A summary of the available heat capacity data is presented in Table 6. To our knowledge, no heat capacity data for 2-(isopropylamino)ethanol were reported in the literature.

The experimental heat capacity data obtained in this work were fitted by the polynomial equation:

$\frac{C_{p, \mathrm{~m}}^{\mathrm{l}}}{R}=\sum_{i=0}^{n} A_{i+1}\left(\frac{T}{100}\right)^{i}$

where $R=8.3144598 \mathrm{~J} \cdot \mathrm{mol}^{-1} \cdot \mathrm{K}^{-1}$ is the molar gas constant [28], $T$ is the absolute temperature, $A_{i+1}$ are the correlation parameters, and $C_{p, \mathrm{~m}}$ denotes the liquid phase heat capacity. The obtained parameters are listed in Table 7 . The comparison of liquid heat capacities obtained in this work with the literature values is shown in 


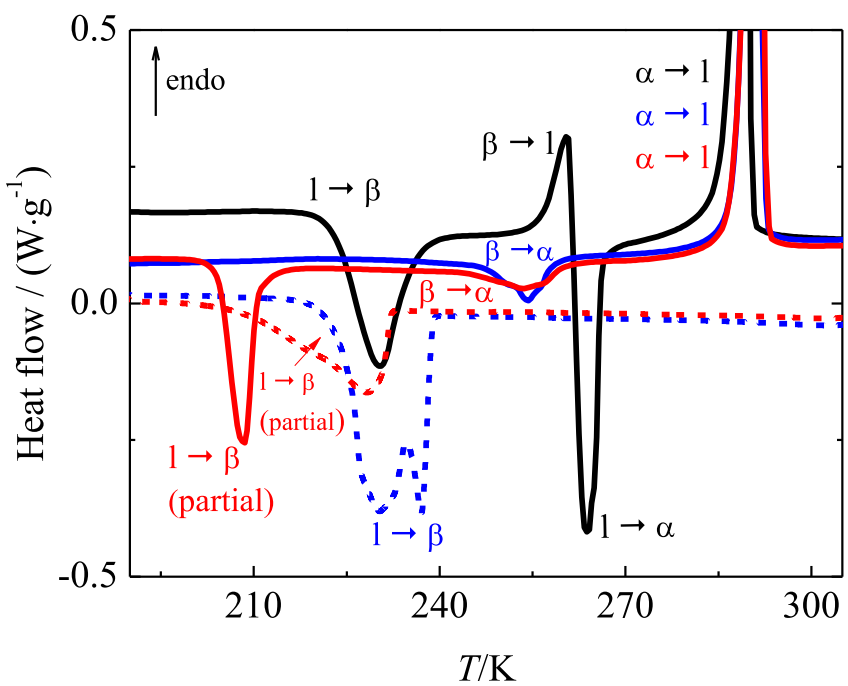

Fig. 5. DSC thermograms for 2-(isopropylamino)ethanol at cooling/heating rate of $2 \mathrm{~K} \cdot \mathrm{min}^{-1}$ in the temperature range $183 \mathrm{~K}-318 \mathrm{~K}-$, experiment $\mathrm{A}(\mathrm{m}=2.50 \mathrm{mg}$, heating from 183 to $318 \mathrm{~K}$, no thermal event was detected during preceding cooling), -.--, experiment B ( $m=2.89 \mathrm{mg}$, cooling from 318 to $183 \mathrm{~K})$, —, experiment B (heating from 183 to $318 \mathrm{~K})$, =--., experiment $\mathrm{C}(\mathrm{m}=3.84 \mathrm{mg}$, cooling from 318 to $183 \mathrm{~K}),-$, experiment $\mathrm{C}$ (heating from 183 to $318 \mathrm{~K}$ ).

Fig. 3. The heat capacity data for 2-(diethylamino)ethanol reported by Steele et al. [10] in a form of linear equation deviate by $1.1-3.2 \%$ in the overlapping temperature interval and those reported by Maham et al. [27] are on average lower by about $1.2 \%$. In the case of 2-(ethylamino)ethanol, the heat capacity data measured by Maham et al. [27] deviate from 0.3 to $-2.8 \%$ in the overlapping temperature range showing thus a different temperature trend than our data. Due to these reasons, only heat capacity data obtained in this work were used in the correlation even though the data by Maham et al. [27] for 2-(diethylamino)ethanol agree with our measurements within combined uncertainty intervals.

\subsection{Phase behavior}

No information about the normal fusion temperatures or phase behavior of the studied compounds was found in the literature. Despite many attempts and various temperature programs applied, 2-(diethylamino)ethanol did not crystallize in the temperature range down to $183 \mathrm{~K}$. Nevertheless, as many organic compounds easily supercool, especially in the case of very small samples, it cannot be ruled out that the fusion temperature lies in the studied temperature range (particularly near the minimum temperature of the working range of the DSC calorimeter i.e. $183 \mathrm{~K}$ ). For both 2(ethylamino)ethanol and 2-(isopropylamino)ethanol, two crystalline monotropically related forms, metastable $\beta$-form and thermodynamically stable $\alpha$-form, were detected as shown in Figs. 4 and 5. As can be seen from Fig. 4, the crystallization of 2-(ethylamino)ethanol was rather a slow process. When cooling the sample by $2 \mathrm{~K} \cdot \mathrm{min}^{-1}$ it traversed the optimal temperature window for crystallization without its completion (Fig. 4a). A further crystallization (cold crystallization) was thus observed on the subsequent heating curve followed by a spontaneous (irreversible) transition from metastable $\beta$-form to the stable $\alpha$-form. When the sample was kept at $233 \mathrm{~K}$ for $60 \mathrm{~min}$, it entirely crystallized to the metastable $\beta$ form which spontaneously transformed to the stable $\alpha$-form during the isotherm (Fig. 4b). Only the fusion of the stable $\alpha$-form $\left(T_{\alpha \rightarrow 1}=\right.$ $\left.(263.9 \pm 0.3) \mathrm{K}, \Delta_{\alpha}^{\mathrm{l}} H_{\mathrm{m}}=(16.5 \pm 0.3) \mathrm{kJ} \cdot \mathrm{mol}^{-1}\right)$ was subsequently obtained when heating the sample by $2 \mathrm{~K} \cdot \mathrm{min}^{-1}$.

Fig. 5 shows DSC thermograms for 2-(isopropylamino)ethanol obtained at the same cooling/heating rate of $2 \mathrm{~K} \cdot \mathrm{min}^{-1}$ in the temperature range $183 \mathrm{~K}-318 \mathrm{~K}$. Despite using the same temperature program in all experiments (the mass of the sample varied from 2.50 to $3.84 \mathrm{mg}$ ) three scenarios were observed, denoted as experiment A, B, and C in Fig. 5. During the experiment A, no crystallization was observed when cooling the sample from melt. On the heating curve, first the crystallization from the melt to the metastable $\beta$-form (cold crystallization) was observed followed by the melting of the metastable $\beta$-form at about $T_{\beta \rightarrow 1}=256 \mathrm{~K}$ overlapping with the crystallization of the stable $\alpha$-form which melted at $T_{\alpha \rightarrow 1}=(289.0 \pm 1.0) \mathrm{K}\left(\Delta_{\alpha}^{1} H_{\mathrm{m}}=(19.0 \pm 1.5) \mathrm{kJ} \cdot \mathrm{mol}^{-1}\right)$. As a direct evaluation of the enthalpy of fusion of the metastable $\beta$-form, $\Delta_{\beta}^{1} H_{\mathrm{m}}$, by an integration of the corresponding melting peak was not possible due to the overlapping thermal events, it was estimated based on the observed crystallization enthalpies $\Delta_{\mathrm{l}}^{\beta} H_{\mathrm{m}}$ at different temperatures and extrapolated to $T_{\beta \rightarrow 1}$. During the experiment $\mathrm{B}$,

Table 8

Phase change temperatures (in $\mathrm{K}$ ) and enthalpies (in $\left.\mathrm{kJ} \cdot \mathrm{mol}^{-1}\right)$ at $p=(100 \pm 5) \mathrm{kPa}$ determined by DSC.

\begin{tabular}{|c|c|c|c|c|c|c|}
\hline Compound & $T_{\beta \rightarrow \alpha}$ & $\Delta_{\beta}^{\alpha} H_{\mathrm{m}}$ & $T_{\beta \rightarrow 1}$ & $\Delta_{\beta}^{1} H_{\mathrm{m}}$ & $T_{\alpha \rightarrow 1}$ & $\Delta_{\alpha}^{1} H_{\mathrm{m}}$ \\
\hline 2-(ethylamino)ethanol & $213-243^{a}$ & $\approx-4$ & - & - & $263.9 \pm 0.3$ & $16.5 \pm 0.3$ \\
\hline 2-(isopropylamino)ethanol & $238-250^{\mathrm{a}}$ & $\approx-2$ & $\approx 256$ & $\approx 14^{\mathrm{b}}$ & $289.0 \pm 1.0^{c}$ & $19.0 \pm 1.5^{c}$ \\
\hline
\end{tabular}

a Typical temperature range of spontaneous transformation of the metastable crystalline $\beta$-form to the stable $\alpha$-form when heating rate ranging from 0.5 to $5 \mathrm{~K} \cdot \mathrm{min}^{-1}$ was applied.

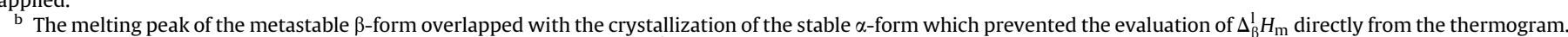

$\Delta_{\beta}^{1} H_{\mathrm{m}}$ was estimated based on the observed crystallization enthalpies $\Delta_{1}^{\beta} H_{\mathrm{m}}$ at different temperatures and extrapolated to $T_{\beta} \rightarrow \mathrm{l}$.

c Higher uncertainty was assigned to these values due to a complex phase behavior of 2-(isopropylamino)ethanol and larger spread of the obtained values.

Table 9

Phase change enthalpies $\Delta H_{\mathrm{m}}$ in $\mathrm{kJ} \cdot \mathrm{mol}^{-1}$ and melting temperatures $T_{\alpha \rightarrow 1}$ in $\mathrm{K}$ derived from the vapor pressure equations and measured calorimetrically.

\begin{tabular}{|c|c|c|c|c|c|c|}
\hline \multirow[t]{2}{*}{ Compound } & \multicolumn{4}{|l|}{ Vapor pressure ${ }^{\mathrm{a}}$} & \multicolumn{2}{|l|}{ DSC } \\
\hline & $\Delta_{1}^{\mathrm{g}} H_{\mathrm{m}}(298.15 \mathrm{~K})$ & $T_{\alpha \rightarrow 1}{ }^{\mathrm{b}}$ & $\Delta_{\alpha}^{\mathrm{g}} H_{\mathrm{m}}\left(T_{\alpha \rightarrow 1}\right)$ & $\Delta_{\alpha}^{1} H_{\mathrm{m}}\left(T_{\alpha \rightarrow 1}\right)^{\mathrm{c}}$ & $T_{\alpha \rightarrow 1}$ & $\Delta_{\alpha}^{1} H_{\mathrm{m}}\left(T_{\alpha \rightarrow 1}\right)$ \\
\hline 2-(diethylamino)ethanol & $52.30 \pm 0.24$ & - & - & - & - & - \\
\hline 2-(ethylamino)ethanol & $60.80 \pm 0.22$ & $265.0 \pm 0.5$ & $80.30 \pm 2.70$ & $17.0 \pm 3.0$ & $263.9 \pm 0.3$ & $16.5 \pm 0.3$ \\
\hline 2-(isopropylamino)ethanol & $63.27 \pm 0.23$ & $290.8 \pm 0.5$ & $78.41 \pm 0.45$ & $14.4 \pm 0.6$ & $289.0 \pm 1.0$ & $19.0 \pm 1.5$ \\
\hline
\end{tabular}

a Calculated using the Cox equation, Eq. (1), with parameters given in Table 4.

b Triple point temperature calculated as an intersection of the vapor pressure equations for crystalline and liquid phases.

c Calculated as $\Delta_{\alpha}^{\mathrm{l}} H_{\mathrm{m}}\left(T_{\alpha \rightarrow 1}\right)=\Delta_{\alpha}^{\mathrm{g}} H_{\mathrm{m}}\left(T_{\alpha \rightarrow 1}\right)-\Delta_{\mathrm{l}}^{\mathrm{g}} H_{\mathrm{m}}\left(T_{\alpha \rightarrow 1}\right)$. 
the sample entirely crystalized on cooling. On the subsequent thermogram obtained on heating, the spontaneous transition from the metastable $\beta$-form to the stable $\alpha$-form was detected followed by its melting. During the experiment $\mathrm{C}$, a slightly different behavior was observed: the sample crystallized only partially on cooling and the process of crystallization was completed on heating. Subsequently, the exothermic transformation $\beta$-form $\rightarrow \alpha$ form and melting of $\alpha$-form were observed. The summary of phase change enthalpies and temperatures is given in Table 8 .

\subsection{Derived thermodynamic properties and mutual consistency of data}

The vaporization and sublimation enthalpies of the studied compounds calculated from the Cox equation, Eq. (1), and ClausiusClapeyron equation are listed in Table 9 and shown in Fig. 6. The molar vaporization enthalpy for 2-(diethylamino)ethanol determined in this work $\Delta_{1}^{\mathrm{g}} H_{\mathrm{m}}(298.15 \mathrm{~K})=(52.30 \pm 0.24) \mathrm{kJ} \cdot \mathrm{mol}^{-1}$ is in good agreement with the value $\Delta_{1}^{\mathrm{g}} H_{\mathrm{m}}(298.15 \mathrm{~K})=(52.50 \pm 0.22)$ $\mathrm{kJ} \cdot \mathrm{mol}^{-1}$ obtained by Steele et al. [10] using their extrapolated vapor pressures and Clapeyron equation, and with $\Delta_{\mathrm{l}}^{\mathrm{g}} H_{\mathrm{m}}(298.15 \mathrm{~K})=(52.5 \pm 0.2) \mathrm{kJ} \cdot \mathrm{mol}^{-1}$ reported by Kapteina et al. [23]. The value determined using the vapor pressure data determined by Lebedeva et al. [20], $\Delta_{l}^{\mathrm{g}} H_{\mathrm{m}}(298.15 \mathrm{~K})=(58.3 \pm 1.3)$ $\mathrm{kJ} \cdot \mathrm{mol}^{-1}$, is in disagreement with all the values reported in the above-mentioned studies. A slightly lower value $\Delta_{\mathrm{l}}^{\mathrm{g}} H_{\mathrm{m}}(298.15 \mathrm{~K})=(52.1 \pm 0.5) \mathrm{kJ} \cdot \mathrm{mol}^{-1}$ would be derived if fitting only vapor pressure data determined in this work, showing the good quality of the data. The vaporization enthalpy of 2-(ethylamino) ethanol derived from the vapor pressure measurements by Kapteina et al. [23] is $\Delta_{l}^{\mathrm{g}} H_{\mathrm{m}}(298.15 \mathrm{~K})=(61.01 \pm 0.44) \mathrm{kJ} \cdot \mathrm{mol}^{-1}$ which is in good agreement with the value derived in this work, $\Delta_{\mathrm{l}}^{\mathrm{g}} H_{\mathrm{m}}(298.15 \mathrm{~K})=(60.80 \pm 0.22) \mathrm{kJ} \cdot \mathrm{mol}^{-1}$. As can be calculated from Table 9 , the specific vaporization enthalpy of the tertiary amine (at $298.15 \mathrm{~K})$ is the lowest $\left(\Delta_{\mathrm{l}}^{\mathrm{g}} h(298.15 \mathrm{~K})=446.3 \mathrm{~J} \cdot \mathrm{g}^{-1}\right)$, most likely due to the absence of possibility of forming donor hydrogen bonding employing the amine group (as already discussed in section 3.1). Consistently, the specific vaporization enthalpies of both secondary amines are notably higher, $\Delta_{1}^{\mathrm{g}} h(298.15 \mathrm{~K})=682.1 \mathrm{~J} \cdot \mathrm{g}^{-1}$ for 2-(ethylamino)ethanol and $\Delta_{l}^{\mathrm{g}} h(298.15 \mathrm{~K})=613.3 \mathrm{~J} \cdot \mathrm{g}^{-1}$ for 2-

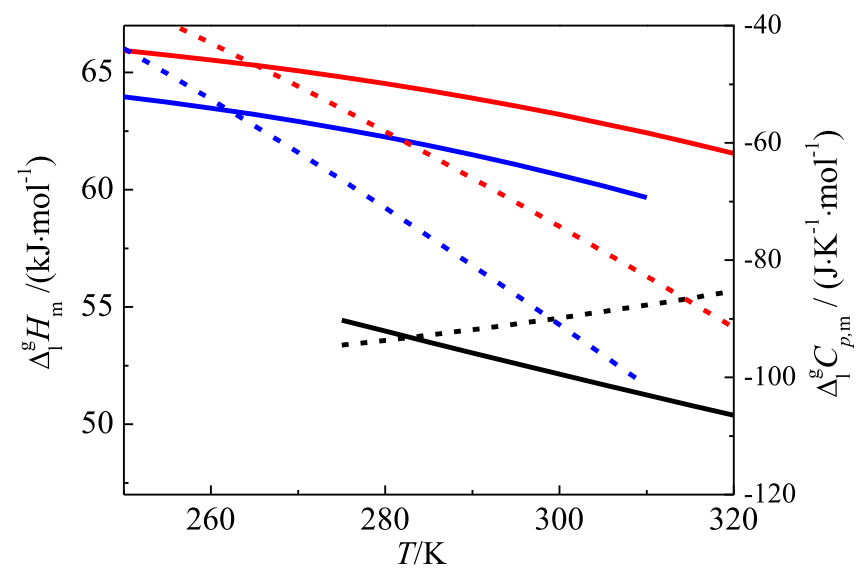

Fig. 6. Vaporization enthalpies $\Delta_{1}^{\mathrm{g}} H_{\mathrm{m}}$ (solid lines, left $y$-axis) and heat capacities $\Delta_{1}^{\mathrm{g}} C_{p, \mathrm{~m}}$ (dashed lines, right $y$-axis) derived from vapor pressure data. - , , , 2-(diethylamino)ethanol, _, -.-., 2-(ethylamino)ethanol, -, -.--, 2-(isopropylamino)ethanol. (isopropylamino)ethanol). The comparison of these two values suggests weaker intermolecular interactions in the case of 2-(isopropylamino)ethanol) reflecting a higher steric hindrance of its amine group. For comparison, the recommended value of $\Delta_{1}^{\mathrm{g}} h$ (298.15 K) for 2-aminoethanol is $996.3 \mathrm{~J} \cdot \mathrm{g}^{-1}$ [26].

The good quality of the vapor pressure determined can be also demonstrated by plotting the derived vaporization enthalpies and heat capacities $\left(\Delta_{1}^{\mathrm{g}} C_{p, \mathrm{~m}}=C_{p, \mathrm{~m}}^{\mathrm{g}}-C_{p, \mathrm{~m}}^{\mathrm{l}}\right)$ as a function of temperature, but to rigorously assess the thermodynamic consistency of vapor pressure data with calorimetric measurements, ideal-gas heat capacities $C_{p, \mathrm{~m}}^{\mathrm{g}}$ are needed. These data were not available in the literature for the studied compounds and their calculation using a combination of quantum-chemical calculations and statistical thermodynamics was not performed in this work due to a very complex conformational space of the studied molecules, and so only a qualitative assessment can be made. $C_{p, \mathrm{~m}}^{\mathrm{g}}$ estimated using the Benson method [29] at $T=300 \mathrm{~K}$ yielded $\Delta_{1}^{\mathrm{g}} C_{p, \mathrm{~m}}=-111 \mathrm{~J} \cdot \mathrm{K}^{-1} \cdot \mathrm{mol}^{-1} \quad$ for $\quad 2$-(diethylamino)ethanol, $\Delta_{1}^{\mathrm{g}} C_{p, \mathrm{~m}}=-102 \mathrm{~J} \cdot \mathrm{K}^{-1} \cdot \mathrm{mol}^{-1}$ for 2-(ethylamino)ethanol, and $\Delta_{1}^{\mathrm{g}} C_{p, \mathrm{~m}}=-111 \mathrm{~J} \cdot \mathrm{K}^{-1} \cdot \mathrm{mol}^{-1}$ for 2-(isopropylamino)ethanol. Taking into account the uncertainties of the estimates using the Benson method (in general group contribution methods are less reliable for molecules with more functional groups) as well as in the calculations of the second derivatives, the above mentioned values are in reasonable agreement with those presented in Fig. 6 showing thus a good consistency of vapor pressure data with heat capacities. For comparison, for 2-aminoethanol $\Delta_{1}^{\mathrm{g}} C_{p, \mathrm{~m}}$ obtained using $C_{p, \mathrm{~m}}^{\mathrm{g}}$ calculated by combination of methods of statistical thermodynamics and quantum chemistry and calorimetrically determined $C_{p, \mathrm{~m}}^{\mathrm{l}}$ amounts to $-83 \mathrm{~J} \cdot \mathrm{K}^{-1} \cdot \mathrm{mol}^{-1}$ at $300 \mathrm{~K}$ [26]. This value is again consistent with the values presented in Fig. 6 .

For 2-(ethylamino)ethanol and 2-(isopropylamino)ethanol, the vapor pressure measurements were also performed in both crystalline (thermodynamically stable $\alpha$-form) and liquid phases which allowed the calculation of the triple point temperatures and enthalpies of fusion at this temperature for these compounds. So obtained values are compared with the calorimetrically determined normal melting temperatures $T_{\alpha \rightarrow 1}$ (which can be considered equal to the triple point temperatures due to a negligible change of melting temperatures with pressure between the triple point pressures and 0.1 MPa) and enthalpies of fusion in Table 9. While for 2-(ethylamino)ethanol the agreement of $T_{\alpha \rightarrow 1}$ as well as enthalpies of fusion $\Delta_{\alpha}^{1} H_{\mathrm{m}}\left(T_{\alpha \rightarrow 1}\right)$ derived using both approaches is satisfactory, $\Delta_{\alpha}^{1} H_{\mathrm{m}}\left(T_{\alpha \rightarrow 1}\right)$ for 2-(isopropylamino)ethanol determined from vapor pressures is significantly lower. The disagreement would even worsen if the vapor pressure data points measured at lowest temperatures were included in the correlation. At this point, the origin of disagreement is not fully understood but due to a rather slow crystallization process it seems possible that the sample was not completely crystallized which led to higher pressure readings.

\section{Conclusions}

New vapor pressure data and liquid phase heat capacities for 2(diethylamino)ethanol, 2-(ethylamino)ethanol, and 2-(isopropylamino)ethanol were determined in this work. For 2-(diethylamino)ethanol, the vapor pressure measurements performed in this work in the range $274-308 \mathrm{~K}$ were combined and correlated together with reliable ebulliometric data from the literature (see Table 3) extending thus the validity of the vapor pressure equation to higher temperatures (up to $476 \mathrm{~K}$ ). For 2-(ethylamino)ethanol 
and 2-(isopropylamino)ethanol only experimental vapor pressures obtained in this work were used in the correlation as no reliable literature data were available (to our knowledge no vapor pressure data were published for 2-(isopropylamino)ethanol). The liquid phase heat capacities measured in this in the temperature range between $265 \mathrm{~K}$ and $355 \mathrm{~K}$ showed a reasonable agreement with the previously published values for 2-(diethylamino)ethanol and 2(ethylamino)ethanol. For 2-(isopropylamino)ethanol, no heat capacity data were available in the literature. The phase behavior studies performed from $183 \mathrm{~K}$ revealed the existence of two monotropically related crystalline forms in the case of 2-(ethylamino) ethanol, and 2-(isopropylamino)ethanol. To our knowledge, their phase behavior including the fusion thermodynamic properties is reported for the first time in this work.

\section{Acknowledgments}

The authors acknowledge financial support from the Czech Science Foundation (GACR no. 17-03875S) and the project POCI-010145-FEDER-006984 - Associate Laboratory LSRE-LCM funded by FEDER through COMPETE2020 - Programa Operacional Competitividade e Internacionalização (POCI) - and by Portuguese national funds through FCT - Fundacão para a Ciência e a Tecnologia.

\section{References}

[1] H. Lepaumier, D. Picq, P.L. Carrette, Degradation study of new solvents for $\mathrm{CO}_{2}$ capture in post-combustion, Energy Procedia 1 (2009) 893-900.

[2] K. Maneeintr, R.O. Idem, P. Tontiwachwuthikul, A.G.H. Wee, Synthesis, solubilities, and cyclic capacities of amino alcohols for $\mathrm{CO}_{2}$ capture from flue gas streams, Energy Procedia 1 (2009) 1327-1334.

[3] I.M. Bernhardsen, H.K. Knuutila, A review of potential amine solvents for $\mathrm{CO}_{2}$ absorption process: absorption capacity, cyclic capacity and pKa, Int. J. Greenh. Gas Control 61 (2017) 27-48.

[4] F.A. Chowdhury, H. Yamada, T. Higashii, K. Goto, M. Onoda, $\mathrm{CO}_{2}$ capture by tertiary amine absorbents: a performance comparison study, Ind. Eng. Chem. Res. 52 (2013) 8323-8331.

[5] P.B. Konduru, P.D. Vaidya, E.Y. Kenig, Kinetics of removal of carbon dioxide by aqueous solutions of N, N -diethylethanolamine and piperazine, Environ. Sci. Technol. 44 (2010) 2138-2143.

[6] N. El Hadri, D.V. Quang, E.L.V. Goetheer, M.R.M. Abu Zahra, Aqueous amine solution characterization for post-combustion $\mathrm{CO}_{2}$ capture process, Appl. Energy 185 (2017) 1433-1449.

[7] K. Goto, F.A. Chowdhury, S. Kodama, H. Okabe, Y. Fujioka, CO2 absorption characteristics of 2-isopropylaminoethanol (IPAE) aqueous solution, in: Recent Adv. Post-Combustion CO2 Capture Chem. Attalla, M.; ACS Symp. Ser. Am. Chem. Soc. Washington, DC, 2012, pp. 71-85.

[8] H. Yamada, F.A. Chowdhury, K. Goto, T. Higashii, $\mathrm{CO}_{2}$ solubility and species distribution in aqueous solutions of 2-(isopropylamino)ethanol and its structural isomers, Int. J. Greenh. Gas Control 17 (2013) 99-105.

[9] H.F. Svendsen, E.T. Hessen, T. Mejdell, Carbon dioxide capture by absorption, challenges and possibilities, Chem. Eng. J. 171 (2011) 718-724.
[10] W.V. Steele, R.D. Chirico, S.E. Knipmeyer, A. Nguyen, Measurements of vapor pressure, heat capacity, and density along the saturation line for cyclopropane carboxylic acid, N,N-Diethylethanolamine, 2,3-dihydrofuran, 5-Hexen-2-one, perfluorobutanoic acid, and 2-phenylpropionaldehyde, J. Chem. Eng. Data 47 (2002) 715-724.

[11] A.I. Papadopoulos, S. Badr, A. Chremos, E. Forte, T. Zarogiannis, P. Seferlis, S. Papadokonstantakis, C.S. Adjiman, A. Galindo, G. Jackson, Efficient screening and selection of post-combustion $\mathrm{CO}_{2}$ capture solvents, Chem. Eng. Trans. 39 (2014) 211-216.

[12] M. Fulem, K. Rủžička, P. Morávek, J. Pangrác, E. Hulicius, B. Kozyrkin V. Shatunov, Vapor pressure of selected organic iodides, J. Chem. Eng. Data 55 (2010) 4780-4784.

[13] V. Štejfa, M. Fulem, K. Ruzicka, P. Morávek, New Static Apparatus for Vapor Pressure Measurements, Reconciled thermophysical data for benzophenone, J. Chem. Eng. Data 61 (2016) 3627-3639.

[14] K. Růžička, M. Fulem, V. Růžička, Recommended vapor pressure of solid naphthalene, J. Chem. Eng. Data 50 (2005) 1956-1970.

[15] K. Růžička, V. Majer, Simultaneous treatment of vapor pressures and related thermal data between the triple and normal boiling temperatures for n-alkanes C5-C20, J. Phys. Chem. Ref. Data 23 (1993) 1-39.

[16] M. Fulem, K. Rủžička, C. Červinka, M.A.A. Rocha, L.M.N.B.F. Santos, R.F. Berg Recommended vapor pressure and thermophysical data for ferrocene, J. Chem. Thermodyn. 57 (2013) 530-540.

[17] G.W.H. Höhne, W.F. Hemminger, H.-J. Flammersheim, Differential Scanning Calorimetry, second ed., Springer Verlag, Berlin, 2003.

[18] M. Straka, K. Rủžička, V. Rủžička, Heat capacities of chloroanilines and chloronitrobenzenes, J. Chem. Eng. Data 52 (2007) 1375-1380.

[19] V. Štejfa, M. Fulem, K. Rǔžička, C. Cervinka, Thermodynamic study of selected monoterpenes III, J. Chem. Thermodyn. 79 (2014) 280-289.

[20] N.D. Lebedeva, L.F. Nazarova, Y.A. Katin, Enthalpies of vaporization of a series of bi- and polyfunctional aliphatic compounds, Termodin. Org. Soedin 6 (1977) 72-73.

[21] C. Yang, Z. Qin, Y. Xu, H. Zeng, F. Sun, P. Zhang, Y. Feng, Isobaric Vapor-Liquid equilibrium for the binary systems of methanol, diethylamine, and $\mathrm{N}, \mathrm{N}-$ Diethylethanolamine at $\mathrm{p}=(60.0$ and 101.3$) \mathrm{kPa}$, J. Chem. Eng. Data 58 (2013) 482-487.

[22] C. Yang, P. Zhang, Z. Qin, Y. Feng, H. Zeng, F. Sun, Isobaric vapor - liquid equilibrium for the binary systems (diethylamine + ethanol), (ethanol $+\mathrm{N}, \mathrm{N}$ - diethylethanolamine), and (diethylamine $+\mathrm{N}, \mathrm{N}$ - diethylethanolamine) at $\mathrm{p}=(80.0$ and 40.0) $\mathrm{kPa}$, J. Chem. Eng. Data 59 (2014) 750-756.

[23] S. Kapteina, K. Slowik, S.P. Verevkin, A. Heintz, Vapor pressures and vaporization enthalpies of a series of ethanolamines, J. Chem. Eng. Data 50 (2005) 398-402.

[24] K. Klepáčová, P.J.G. Huttenhuis, P.W.J. Derks, G.F. Versteeg, Vapor pressures of several commercially used alkanolamines, J. Chem. Eng. Data 56 (2011) $2242-2248$.

[25] E.R. Cox, Pressure-temperature chart for hydrocarbon vapors, Ind. Eng. Chem. 15 (1923) 592-593.

[26] K. Růžička, M. Fulem, T. Mahnel, C. Červinka, Recommended vapor pressures for aniline, nitromethane, 2-aminoethanol, and 1-methyl-2-pyrrolidone, Fluid Phase Equil. 406 (2015) 34-46.

[27] Y. Maham, L.G. Hepler, A.E. Mather, A.W. Hakin, R.A. Marriott, Molar heat capacities of alkanolamines from 299.1 to 397.8 K Group additivity and molecular connectivity analyses, J. Chem. Soc., Faraday Trans. 93 (1997) $1747-1750$.

[28] P.J. Mohr, D.B. Newell, B.N. Taylor, CODATA recommended values of the fundamental physical constants 2014, Rev. Mod. Phys. 88 (2016) 1-73.

[29] S.W. Benson, Thermochemical Kinetics: Methods for the Estimation of Thermochemical Data and Rate Parameters, second ed., Wiley, New York, 1976. 